\title{
No association between periodontal disease and GHQ-12 in a Brazilian Police population
}

\author{
Eliane-Lopes Godinho ${ }^{1,2}$, Lucyana-Conceição Farias ${ }^{1}$, João-Carlos-Andrade Aguiar ${ }^{1}$, Hercílio Martelli- \\ Júnior ${ }^{1}$, Paulo-Rogério-Ferreti Bonan ${ }^{1}$, Raquel-Conceição Ferreira ${ }^{1}$, Alfredo-Maurício-Batista De Paula ${ }^{1}$, \\ Andréa-Maria-Eleutério de Barros-Lima Martins ${ }^{2}$, André-Luiz-Sena Guimarães ${ }^{1}$
}

Correspondence:

Universidade Estadual de Montes Claros

Hospital Universitário Clemente de Faria

Laboratório de Pesquisa em Saúde

Avenida Cula Mangabeira, 562

Montes Claros

Minas Gerais, Brasil

cep 39401-001

andreluizguimaraes@gmail.com

\begin{abstract}
Godinho EL, Farias LC, Aguiar JCA, Martelli-Júnior H, Bonan PRF, Ferreira RC, De Paula AMB, Martins AMEL, Guimarães ALS. No association between periodontal disease and GHQ-12 in a Brazilian Police population. Med Oral Patol Oral Cir Bucal. 2011 Sep 1;16 (6):e857-63. http://www.medicinaoral.com/medoralfree01/v16i6/medoralv16i6p857.pdf
\end{abstract}

Received: 28/06/2010

Accepted: $26 / 08 / 2010$

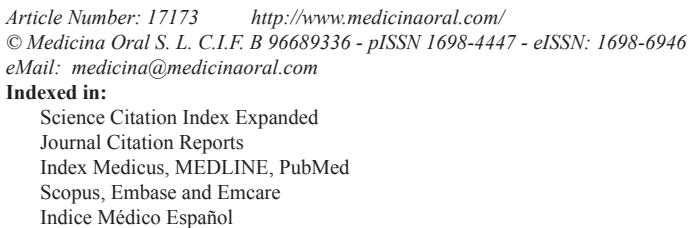

\begin{abstract}
Objectives: We attempt to investigate a possible association between periodontal disease (PD) and mental disorders (MD) in a population of Brazilian Police.

Study Method: From a total study population consisting of 803 policemen, 345 police officers were obtained by a sample calculation using the finite population correction who were randomly selected in Montes Claros, Minas Gerais, Brazil. Patients who had been prescribed steroids or those diagnosed with diabetes and cardiovascular diseases were excluded from this study. The General Health Questionnaire (GHQ-12) was used to assess mental disorders. Odds ratios (ORs) for periodontal diseases severity and their respective 95\% confidence intervals (CIs) were estimated. The risk of advanced scores in Clinical Attachment Level (CAL) and Community Periodontal Index (CPI) were estimated using Poisson Regression analyses.

Results: Only smoking and age were associated with severity in CAL and CPI index. No relation between MD and PD was observed even in different positions within the police department.

Conclusions: It was not observed relation between GHQ-12 and the incidence of Periodontal Disease in a Brazilian Police population. Classical factors like age and smoking, however, were associated with CAL and CPI index higher scores in this population.
\end{abstract}

Key words: Periodontal disease, GHQ-12, mental disorder, Police.

\section{Introduction}

Periodontal disease (PD) is a multifactorial disease characterized by inflammation and destruction of tooth supporting tissues, as a result of the response of a susceptible host to bacterial challenge (1). It is one of the most common causes of tooth loss in the world (2). Some risk factors, such as diabetes mellitus, smoking, age, genetic and epigenetic factors may influence the onset and progression of periodontal disease (3-6).
Evidences suggest that Mental Disorders (MD) such as depression, stress, anxiety, and occupational stress might contribute to the development of PD (7-11). It could be explained by the fact of immune system is controlled and regulated by bi-directional brain-to-immune communication mechanisms $(12,13)$. In order to test this hypothesis, numerous studies using a variety of approaches were performed over the past several decades (3-5, 13-15) but until now the role of $\mathrm{MD}$ in $\mathrm{PD}$ remains unclear. 
Police activity involves frequent exposure to potentially traumatic situations, such as armed confrontations, motor vehicle crashes and witnessing violent deaths (16, 17). Moreover, policeman prevalence rates of stress disorder are similar in different countries besides the marked differences in assessment methodology, local levels of violence, the quality and the duration of the training, sociocultural factors in general exceed those found in the general population (16). Since, until now, no article attempt to investigate the association between PD and MD in a police population. The purpose of the current article is to investigate a possible association between PD and MD in a population of Brazilian Police.

\section{Patients and Methods}

The total study population consisted of 803 policemen from Montes Claros, Minas Gerais, Brazil. Patients who had been prescribed steroids or those diagnosed with diabetes and cardiovascular diseases were excluded from this study. All patients have access to psychological, medical and dentistry services. The number of participants was defined by a sample calculation using the finite population correction and a total number of 345 police officers was obtained, who were randomly selected.

\section{-Data Collection}

The data were collected by means of an interview with the police officers and examination of the oral cavity after obtaining the term of free and informed consent. Specific software developed by Martins AMEBL was used to collect all data from September 2008 to July 2009. All data collection was performed by a single trained and calibrated researcher. The calibration of the observer was measured by Kappa statistics.

\section{-Sociodemographic and behavioral variables}

The sociodemographic conditions assessed were age, marital status, sex, race, years of education, per capita income, years working for the police corporation, type of job and police officer rank. Satisfaction with oral condition was assessed by the following question: "How satisfied are you with your oral health?" This variable was dichotomized as positive (very satisfied, satisfied, neither satisfied nor dissatisfied) and negative (dissatisfied, very dissatisfied). Tobacco and drink habit were classified as used before (18). Only those patients who had never smoked were considered non-smokers. Ex-drinkers and ex-smokers were subjects who had abstained from any type of drinking and smoking for at least one year. Oral hygiene was categorized in 3 groups according to types of additional methods than the use of toothbrush in: Type 1 (use of tongue cleaner and dental floss), Type 2 (use dental floss) and Type 3 (use tongue cleaner). Physical description of skin color was not used because it is a poor predictor of genomic ancestry in Brazil (19).

\section{-Mental Disorders}

The General Health Questionnaire (GHQ-12) for triage of mental disorders, translated into Portuguese and validated in Brazil was used (20). The 12th-item is a selfreport scale for nonpsychotic, minor mental illness that is also used as a general measurement of psychological well-being (21). Each item of the GHQ-12 ranges from $0-2,3-5,6+$. A simple scoring method was used for the 12 questions of $0-0-1-1(0=$ absence of common mental disorders, $1=$ presence). Its total score ranges from 0 to 12 and the higher the score, the worse the mental health. The patients were divided in three groups according GHQ scores in less than 2 (typical scores), between 3 and 6 (evidence of distress) and more than 6 (suggests severe problems and psychological distress) as described before (20).

\section{-Periodontal Disease}

Assessment of periodontal disease was conducted using the Community Periodontal Index (CPI) and periodontal clinical attachment loss index (CAL). For the CPI and CAL assessment, standardized criteria established by the World Health Organization in 1997 were used (2,22). To perform periodontal examinations, the oral cavity was divided into sextants and six sites per tooth were assessed (mesiobuccal, mid-buccal, disto-buccal, disto-lingual, mid-lingual and mediolingual sites), using the periodontal probe to measure pocket depth and Clinical Attachment Level (CAL). A periodontal pocket was defined as the distance from the free gingival margin to the base of the pocket/sulcus. Clinical Attachment Level was defined as the distance (in millimeters) from the cement-enamel junction to the base of the pocket/sulcus. Each sextant received a score according to the worst condition presented: according to the CPI index $(0=$ healthy sextant, $1=$ sextant with bleeding, 2 = calculus, $3=$ pocket from $4 \mathrm{~mm}$ to $5 \mathrm{~mm}$, $4=$ pocket $\geq 6 \mathrm{~mm})$ and $\mathrm{CAL}(0=$ clinical attachment loss of $\leq 3,1=$ clinical attachment loss between 4 and $5 \mathrm{~mm}, 2=$ clinical attachment loss between $6 \mathrm{~mm}$ and 8 $\mathrm{mm}, 3=$ clinical attachment loss between $9 \mathrm{~mm}$ and 11 $\mathrm{mm}, 4=$ clinical attachment loss of $\geq 12 \mathrm{~mm}$ ).

The data collection was conducted in accordance with the ethical principles contained in the Helsinki Declaration, 1964. Ethical approval for this study was obtained from the local Ethics Committee (Unimontes/COEP, 1134/2008).

\section{-Statistical analysis}

Initially the police officers were characterized as regards the variables investigated. With regard to periodontal health, the police officers were divided into not ill (CPI $\leq 2$ - presence of calculus, and $\mathrm{CAL}<2$ - clinical attachment loss between 0 and $5 \mathrm{~mm}$ ) and ill (CPI $\geq 3$ pocket, and CAL $\geq 2$ - clinical attachment loss of $\geq 6$ $\mathrm{mm})$. Next, bivariate and multivariate analyses were performed in an endeavor to identify the factors as- 
sociated with the periodontal condition. The variables that showed significant relationship with periodontal disease, with $p$-values lower than 0.25 in the bivariate analysis were included in the multivariate analysis in a decreasing order of the descriptive level. The final model was composed of factors that remained associated with the normative need for dental treatment at a level of 0.05 $(\mathrm{p}<0.05)$. The multivariate analysis was performed by the Poisson regression (23). Analysis was performed with the statistical program SPSS ${ }^{\circledR}$ 17.0.

\section{Results}

The Cronbach's alpha of GHQ-12 was 0.998 indicating internal consistency of the scale (data not shown). The concordance obtained by kappa test was 0.84 . The descriptive data are shown in table 1.

In bivariate analyze no associations with GHQ-12 were observed with CAL or CPI index. Only higher age and the presence of smoking were associated with high scores of both CAL and CPI. Taken CPI index isolated, lower level of education and the absence use of tongue cleaner or dental floss were also associated with higher CPI scores. On the other hand, time in the police and alcohol consumption were the other variables associated with CAL higher scores (Table 2).

In multivariate analyze, GHQ-12 were no associated with CAL or CPI index (table 3). After adjusting the model to the best significance, only age and smoking habit have had impact on CPI and CAL. Smoke could increase the risck of LOA in 2.69 times and the risk of CPI in 1.65 times. Additionally, the less complex types of oral hygiene were associated with higher CPI index.

\section{Discussion}

Over the past several decades, a plethora of information concerning the influence of MD on the loss of dental attachment has been made available in the literature $(3,4$, $8,9,11,13,14)$. But until now the biological mechanisms to explain this association remains unclear. Evidences suggest that genetic, epigenetic and environmental conditions might be involved in bone resorption rates and could interfere in PD progression (4-6). In the current study no association between MD and PD was observed. Moreover, no association between type of work on the police (action or administrative) and CPI index or CAL were observed. Our data could be explained by the fact that the population analyzed here has access to frequent to psychological, medical and dentistry preventive/curative programs and selection bias. Another important factor is that we could not established the ancestry by physical description of skin color because the degree of a mixed-race of Brazilian population (19, 24). Difficulties to compare studies are attributed to the differences in definition of periodontal disease adopted, the diagnostic criteria used to access prevalence of MD and the preventives support given our population. We could compare the data of the current study with Chiou et al. (11), who observed that poor mental health had a stronger association with periodontal disease among smokers than among nonsmokers, especially in accumulative CAL. But it is important to highlight that no risk of MD patients were used in this study (11). Taken that the prevalence of some stress disorders are similar in policemen from different countries and generally exceed those found in the general population $(16,25)$, we could speculate that the local treatment and prevention could be sufficient to avoid the PD progression in MD patients. But it is important to emphasize that the results observed in animal models shed light on the possible role of antidepressant treatment to reduce attachment loss (13). To understand how the best approach for PD in MD patients, more studies with specifically MD diagnoses and molecular tests are necessary.

Although no association with GHQ scores were observed here, it was shown that smoking was important to attachment loss. Classically the synergism between smoking and attachment loss has been described (11). Smoking is associated with a two to eight-fold increased risk for periodontal attachment and/or bone loss, depending on the definition of disease severity and smoking dose (26). Tobacco smoking may provide mechanisms for the increased susceptibility to periodontitis and the poorer response to treatment (27). It seems that nicotine might increase expression of proinflammatory cytokine and consequently accelerate CAL (28). In the current study it was observed the association with smoke habbit increase in two fold risk of CAL.

Our data suggest that age could increase CAL high scores. This finding might sound obvious because the importance of age in the evaluation of the nature of an individual's periodontal disease (2). But past controversies associated with age on the PD classification (2) suggest that this data must be cautiously analyzed.

In the current study absence of use dental floss or tongue cleaner was associated with higher CPI index. The importance of dental hygiene in the etiology of gingival inflammation was classically demonstrated before (29). Although frequent dentistry preventive programs, only $25.4 \%$ of the population followed the correct oral hygiene method prescribed. As few people can sustain the dedication required to consistently perform this mechanical tooth-cleaning regimen Mechanical Oral Hygiene could be useful in prevention of gingivitis and consequently PD (30).

In conclusion, it was not observed relation between Mental Disorders and the incidence of Periodontal Disease in a population of Brazilian Police, although in this population classical factors like age and smoking were associated with CAL and CPI index higher scores. 
Table 1. Data distribution.

\begin{tabular}{|c|c|c|c|}
\hline Variables & Category & $\mathbf{n}$ & $\%$ \\
\hline \multirow[t]{2}{*}{$\mathrm{CAL}$} & Nondisease & 317 & 92.1 \\
\hline & Disease & 28 & 7.9 \\
\hline \multirow[t]{2}{*}{$\mathrm{CPI}$} & Nondisease & 285 & 82.7 \\
\hline & Disease & 60 & 17.3 \\
\hline \multirow[t]{3}{*}{ GHQ score } & less than 2 & 271 & 78.6 \\
\hline & between 3 and 6 & 51 & 14.8 \\
\hline & more than 6 & 23 & 6.7 \\
\hline \multirow[t]{2}{*}{ Age } & $20-37$ & 192 & 55.5 \\
\hline & $38-53$ & 153 & 44.3 \\
\hline \multirow[t]{2}{*}{ Marital Status } & Married & 273 & 79.1 \\
\hline & Other & 72 & 20.9 \\
\hline \multirow[t]{2}{*}{ Gender } & Female & 17 & 4.9 \\
\hline & Male & 328 & 95.1 \\
\hline \multirow[t]{2}{*}{ Years studing } & $\geq 12$ & 92 & 26.8 \\
\hline & $<12$ & 253 & 73.2 \\
\hline \multirow[t]{2}{*}{ Salary per capta in family } & $740-4500$ & 170 & 49.3 \\
\hline & $280-738$ & 175 & 50.7 \\
\hline \multirow[t]{2}{*}{ Satisfaction with condition mouth } & Positive & 305 & 88.4 \\
\hline & Negative & 40 & 11.6 \\
\hline \multirow[t]{2}{*}{ Smoke } & No & 285 & 82.6 \\
\hline & Yes & 60 & 17.4 \\
\hline \multirow[t]{2}{*}{ Alchool consumption } & No & 75 & 21.7 \\
\hline & Yes & 270 & 78.3 \\
\hline \multirow[t]{2}{*}{ work years of Police } & less than 14 & 136 & 39.4 \\
\hline & more than 15 & 209 & 60.6 \\
\hline \multirow[t]{2}{*}{ Hygiene } & more than 2 times & 289 & 84.3 \\
\hline & 1 a 2 times & 56 & 15.7 \\
\hline \multirow[t]{3}{*}{ Type of hygiene } & Type 1 & 89 & 25.4 \\
\hline & Type 2 & 130 & 37.9 \\
\hline & Type 3 & 126 & 36.7 \\
\hline \multirow[t]{3}{*}{ Type of work } & Administrative & 36 & 10.6 \\
\hline & Both & 12 & 2.3 \\
\hline & Action & 297 & 87.1 \\
\hline
\end{tabular}




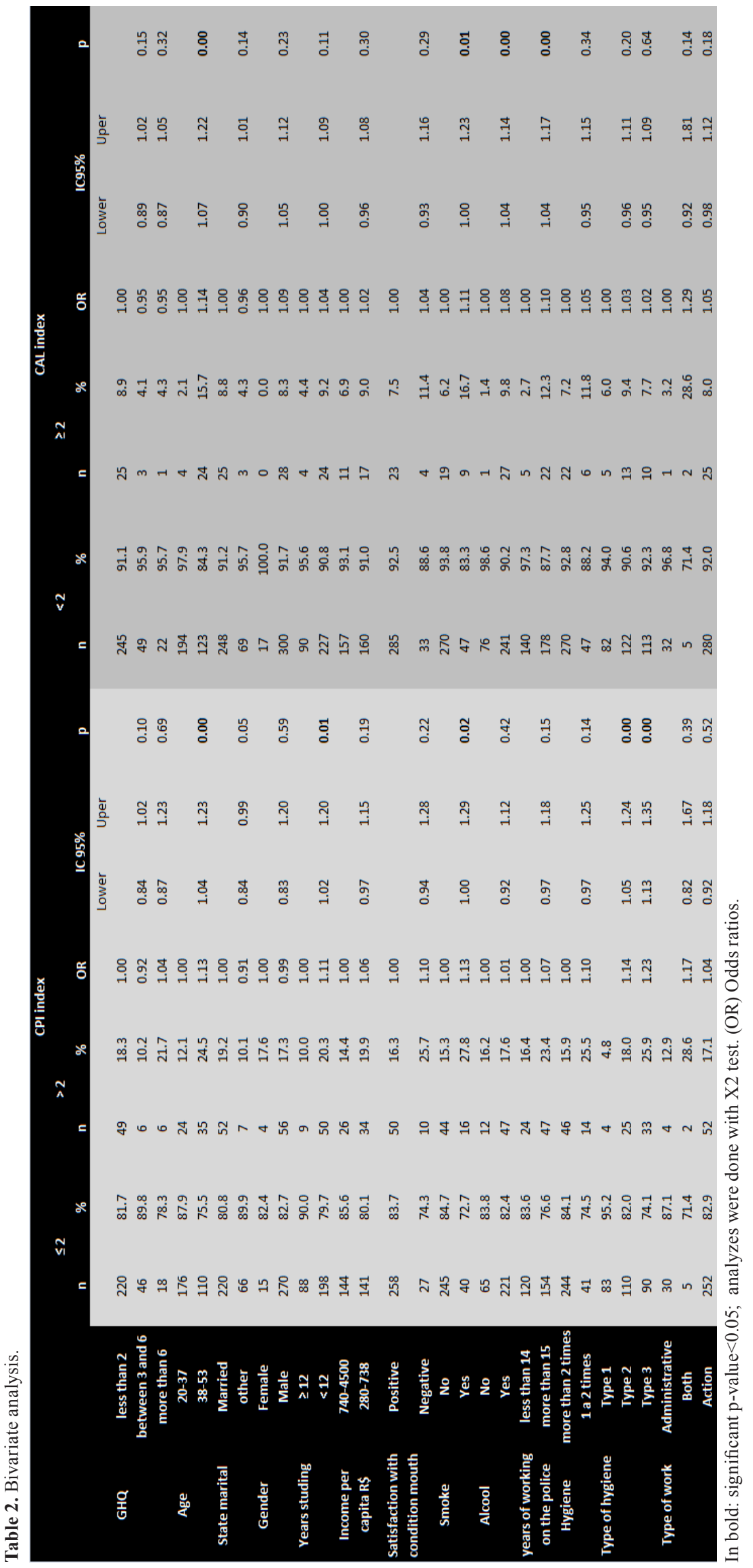


Table 3. Multivariate analysis demonstrating the variables associated with risk of Community Periodontal Index $\geq 3 \mathrm{~mm}$ and clinical attachment loss of $\geq 6 \mathrm{~mm}$.

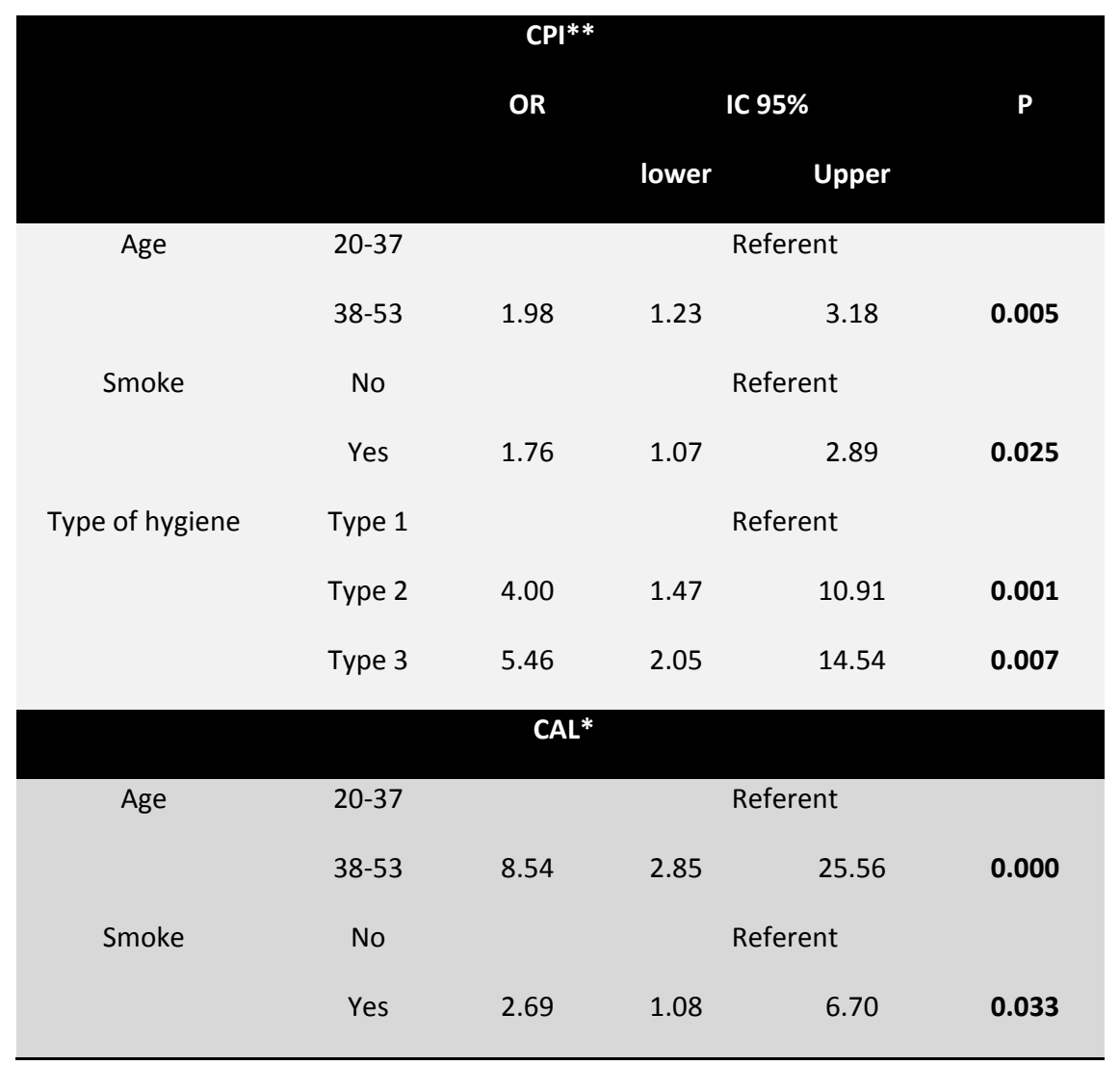

In bold: significant $\mathrm{p}$-value $<0.05 *$ Analyzed by Poisson Regression ** analyzed by Logistic regression. (OR) Odds ratios.

\section{References}

\section{References with links to Crossref - DOI}

1. Borrell LN, Papapanou PN. Analytical epidemiology of periodontitis. J Clin Periodontol. 2005;32Suppl 6:132-58.

2. Armitage GC. Periodontal diagnoses and classification of periodontal diseases. Periodontol 2000. 2004;34:9-21.

3. Rosania AE, Low KG, McCormick CM, Rosania DA. Stress, depression, cortisol, and periodontal disease. J Periodontol. 2009;80:260-6.

4. Costa JE, Gomes CC, Cota LO, Pataro AL, Silva JF, Gomez RS, et al. Polymorphism in the promoter region of the gene for 5-HTT in individuals with aggressive periodontitis. J Oral Sci. 2008;50:193-8. 5. Dutra WO, Moreira PR, Souza PE, Gollob KJ, Gomez RS. Implications of cytokine gene polymorphisms on the orchestration of the immune response: lessons learned from oral diseases. Cytokine Growth Factor Rev. 2009;20:223-32.

6. Gomez RS, Dutra WO, Moreira PR. Epigenetics and periodontal disease: future perspectives. Inflamm Res. 2009;58:625-9.

7. Peruzzo DC, Benatti BB, Ambrosano GM, Nogueira-Filho GR, Sallum EA, Casati MZ, et al. A systematic review of stress and psychological factors as possible risk factors for periodontal disease. J Periodontol. 2007;78:1491-504.

8. Dolic M, Bailer J, Staehle HJ, Eickholz P. Psychosocial factors as risk indicators of periodontitis. J Clin Periodontol. 2005;32:1134-40. 9. Green LW, Tryon WW, Marks B, Huryn J. Periodontal disease as a function of life events stress. J Human Stress. 1986;12:32-6.

10. Persson GR, Persson RE, MacEntee CI, Wyatt CC, Hollender LG, Kiyak HA. Periodontitis and perceived risk for periodontitis in elders with evidence of depression. J Clin Periodontol. 2003;30:691-6. 11. Chiou LJ, Yang YH, Hung HC, Tsai CC, Shieh TY, Wu YM, et al. The association of psychosocial factors and smoking with periodontal health in a community population. J Periodontal Res. 2010;45:1622.

12. Pavlov VA, Tracey KJ. Neural regulators of innate immune responses and inflammation. Cell Mol Life Sci. 2004;61:2322-31.

13. Breivik T, Gundersen Y, Myhrer T, Fonnum F, Osmundsen H, Murison R, et al. Enhanced susceptibility to periodontitis in an animal model of depression: reversed by chronic treatment with the anti-depressant tianeptine. J Clin Periodontol. 2006;33:469-77.

14. Genco RJ, Ho AW, Grossi SG, Dunford RG, Tedesco LA. Relationship of stress, distress and inadequate coping behaviors to periodontal disease. J Periodontol. 1999;70:711-23.

15. Keyes CL. Mental illness and/or mental health? Investigating axioms of the complete state model of health. J Consult Clin Psychol. 2005;73:539-48.

16. Maia DB, Marmar CR, Metzler T, Nóbrega A, Berger W, Mendlowicz MV, et al. Post-traumatic stress symptoms in an elite unit of Brazilian police officers: prevalence and impact on psychosocial functioning and on physical and mental health. J Affect Disord. 2007;97:241-5.

17. Carlier IV, Lamberts RD, Gersons BP. The dimensionality of trauma: a multidimensional scaling comparison of police officers with and without posttraumatic stress disorder. Psychiatry Res. 2000;97:29-39.

18. De Paula AM, Souza LR, Farias LC, Corrêa GT, Fraga CA, Eleutério NB, et al. Analysis of 724 cases of primary head and neck squamous cell carcinoma (HNSCC) with a focus on young patients and 
p53 immunolocalization. Oral Oncol. 2009;45:777-82.

19. Parra FC, Amado RC, Lambertucci JR, Rocha J, Antunes CM, Pena SD. Color and genomic ancestry in Brazilians. Proc Natl Acad Sci U S A. 2003;100:177-82.

20. Mari JJ, Williams P. A comparison of the validity of two psychiatric screening questionnaires (GHQ-12 and SRQ-20) in Brazil, using Relative Operating Characteristic (ROC) analysis. Psychol Med. 1985;15:651-9.

21. Goldberg DP, Gater R, Sartorius N, Ustun TB, Piccinelli M, Gureje $\mathrm{O}$, et al. The validity of two versions of the GHQ in the WHO study of mental illness in general health care. Psychol Med. 1997;27:191-7. 22. Peres MA, Antunes JL, Boing AF, Peres KG, Bastos JL. Skin colour is associated with periodontal disease in Brazilian adults: a population-based oral health survey. J Clin Periodontol. 2007;34:196201.

23. McNutt LA, Wu C, Xue X, Hafner JP. Estimating the relative risk in cohort studies and clinical trials of common outcomes. Am J Epidemiol. 2003;157:940-3.

24. Pimenta JR, Zuccherato LW, Debes AA, Maselli L, Soares RP, Moura-Neto RS, et al. Color and genomic ancestry in Brazilians: a study with forensic microsatellites. Hum Hered. 2006;62:190-5.

25. Stein MB, Walker JR, Hazen AL, Forde DR. Full and partial posttraumatic stress disorder: findings from a community survey. Am J Psychiatry. 1997;154:1114-9.

26. Johnson GK, Guthmiller JM. The impact of cigarette smoking on periodontal disease and treatment. Periodontol 2000. 2007;44:17894.

27. Palmer RM, Wilson RF, Hasan AS, Scott DA. Mechanisms of action of environmental factors--tobacco smoking. J Clin Periodontol. 2005;32 Supp16:180-95.

28. Wendell KJ, Stein SH. Regulation of cytokine production in human gingival fibroblasts following treatment with nicotine and lipopolysaccharide. J Periodontol. 2001;72:1038-44.

29. Loe H, Theilade E, Jensen SB. Experimental gingivitis in man. J Periodontol. 1965;36:177-87.

30. Rosema NA, Timmerman MF, Versteeg PA, Van Palenstein Helderman WH, Van der Velden U, Van der Weijden GA. Comparison of the use of different modes of mechanical oral hygiene in prevention of plaque and gingivitis. J Periodontol. 2008;79:1386-94.

\section{Acknowledgments}

This study was supported by grants from Conselho Nacional de Desenvolvimento Científico e Tecnológico $(\mathrm{CNPq})$ and Fundação de Amparo a Pesquisa do Estado de Minas Gerais (FAPEMIG). Dr Guimarães and Martelli-Júnior are research fellow of CNPq. Dr De Paula, Dr. Bonan and Dra. Martins are research fellow of FAPEMIG. 